\title{
Giant hepatic hydatid cyst
}

\section{Ranendra Hajong • Donkupar Khongwar}

Published online: 13 May 2012

(C) Indian Society of Gastroenterology 2012

Hydatid disease is endemic in tropical and subtropical regions. Humans are accidental hosts of this parasite. Hydatid cyst may be asymptomatic, or may cause abdominal pain, jaundice or a visible abdominal mass [1]. Large cysts are prone to perforation and surgical management is preferred. Our patient, a 30-year-old-man weighing $40 \mathrm{~kg}$, presented to us with the complaint of a huge abdominal swelling of 2 years' duration. Computed tomography of abdomen showed a huge type III hydatid cyst originating from the liver (Fig. 1). Intraoperatively, about 6 litres of fluid was aspirated from the cyst cavity, and pericystectomy with omentopexy was done. The diameter of the cyst was approximately $30 \mathrm{~cm}$. A variety of surgical procedures are used to manage the residual cavity after cystectomy. These include hepatic resection, pericystectomy, partial cystectomy combined with omentoplasty, suture obliteration (capitonnage), introflexion, cystojejunostomy, marsupialization, external drainage and primary closure after instillation of saline solution [2]. The strong possibility of a residual cavity after percutaneous treatment limits the use of this form of therapy for large cysts. Pericystectomy was performed for our patient and the resultant cavity was sandwiched with omentum. The patient did well after surgery and had gained $8 \mathrm{~kg}$ of weight when reviewed 6 months after operation.

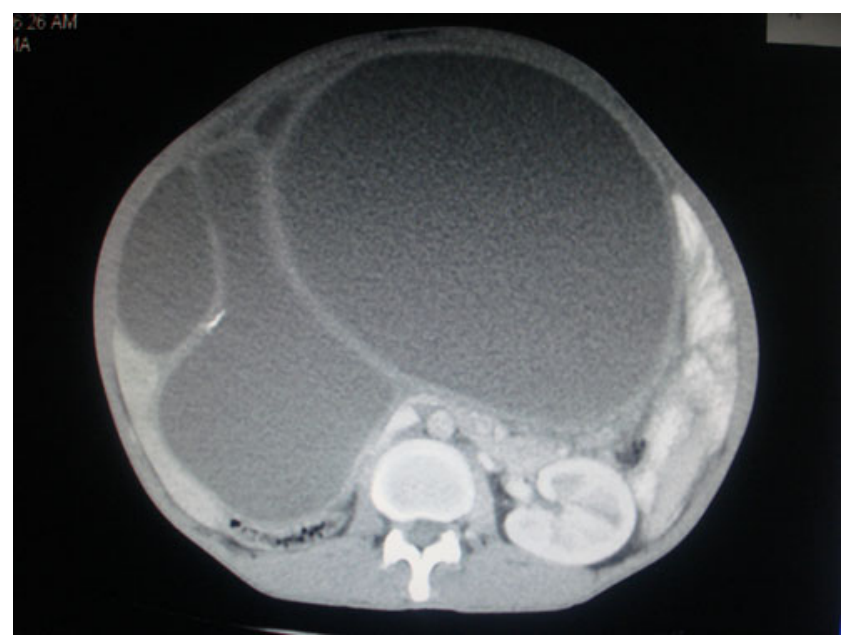

Fig. 1 Contrast-enhanced computed tomography image showing a huge type III hydatid cyst in the liver

\section{References}

1. Yalin R, Aktan AO, Yegen C, Dosluogo HH. Significance of intracystic pressure in abdominal hydatid disease. Br J Surg. 1992;79:1182-3.

2. Elbir O, Gundogdu H, Caglikulekci M, et al. Surgical treatment of intrabiliary rupture of hydatid cysts of liver: comparison of choledochoduodenostomy with T-tube drainage. Dig Surg. 2001;18:289-93.
R. Hajong $(\bowtie) \cdot$ D. Khongwar

Department of Surgery, NEIGRIHMS,

Shillong 793 018, India

e-mail: ranenhajong@gmail.com 